Supporting Information

\title{
Affinity control of mono-saccharide conjugated peptides against lectins with a set of amino acid substitutions on $\alpha$-helical structures
}

Yusuke Maeda, ${ }^{\#}$ Toshiki Sawada,,$+\uparrow$ Tsuyoshi Takahashi, ${ }^{\ddagger}$ Hideya Yuasa, Hisakazu Mihara* Department of Life Science and Technology, School of Life Science and Technology, Tokyo Institute of Technology

\section{E-mail: hmihara@bio.titech.ac.jp}

Proofs to: Prof. Hisakazu Mihara

Department of Life Science and Technology,

School of Life Science and Chemical Technology,

Tokyo Institute of Technology

4259-B-40 Nagatsuta-cho, Midori-ku, Yokohama (Japan)

Tel \& Fax: +81-45-924-5756

E-mail: hmihara@bio.titech.ac.jp

\#These authors contributed to this work equally.

Present address: $\dagger$ Department of Chemical Science and Engineering, School of Materials and Chemical Technology, Tokyo Institute of Technology

$\$$ Department of Chemistry and Chemical Biology, Graduate School of Science and Technology, Gunma University 
Table S1 Identification of peptide by MALDI TOF-MS

\begin{tabular}{lll}
\hline Peptide & $M_{\text {w calcd }}$ & $\mathrm{m} / \mathrm{z}_{\text {obsd }}$ \\
WEM-rand & 1790.0 & $1793.0\left([\mathrm{M}+\mathrm{H}]^{+}\right)$ \\
WEM- $\beta$ & 2084.6 & $2086.6\left([\mathrm{M}+\mathrm{H}]^{+}\right)$ \\
WEM- $\alpha 0$ & 2084.6 & $2087.1\left([\mathrm{M}+\mathrm{H}]^{+}\right)$ \\
WEM- $\alpha 1$ & 2085.5 & $2110.7\left([\mathrm{M}+\mathrm{Na}]^{+}\right)$ \\
WEM- $\alpha 2$ & 2085.5 & $2087.3\left([\mathrm{M}+\mathrm{H}]^{+}\right)$ \\
SEM- $\alpha 1$ & 1985.4 & $1988.7\left([\mathrm{M}+\mathrm{H}]^{+}\right)$ \\
LEM- $\alpha 1$ & 2011.5 & $2012.4\left([\mathrm{M}+\mathrm{H}]^{+}\right)$ \\
WKM- $\alpha 1$ & 2083.6 & $2108.6\left([\mathrm{M}+\mathrm{Na}]^{+}\right)$ \\
LKM- $\alpha 0$ & 2010.6 & $2014.8\left([\mathrm{M}+\mathrm{H}]^{+}\right)$ \\
WEM- $\alpha 1 \mathrm{~F}$ & 2118.6 & $2142.3\left([\mathrm{M}+\mathrm{Na}]^{+}\right)$ \\
WEG-rand & 1790.0 & $1792.4\left([\mathrm{M}+\mathrm{H}]^{+}\right)$ \\
WEG- $\beta$ & 2084.6 & $2109.9\left([\mathrm{M}+\mathrm{Na}]^{+}\right)$ \\
WEG- $\alpha 1$ & 2084.6 & $2087.9\left([\mathrm{M}+\mathrm{H}]^{+}\right)$ \\
SEG- $\alpha 1$ & 1985.4 & $1989.8\left([\mathrm{M}+\mathrm{H}]^{+}\right)$ \\
WKG- $\alpha 0$ & 2083.6 & $2108.6\left([\mathrm{M}+\mathrm{Na}]^{+}\right)$ \\
LKG- $\alpha 0$ & 2010.6 & $2013.9\left([\mathrm{M}+\mathrm{H}]^{+}\right)$ \\
WEG- $\alpha 1-1 \mathrm{Q}$ & 2084.5 & $2085.7\left([\mathrm{M}+\mathrm{H}]^{+}\right)$ \\
WEG- $\alpha 1-2 \mathrm{Q}$ & 2084.5 & $2085.6\left([\mathrm{M}+\mathrm{H}]^{+}\right)$ \\
WEG- $\alpha 1-3 \mathrm{Q}$ & 2085.4 & $2085.5\left([\mathrm{M}+\mathrm{H}]^{+}\right)$ \\
\hline
\end{tabular}




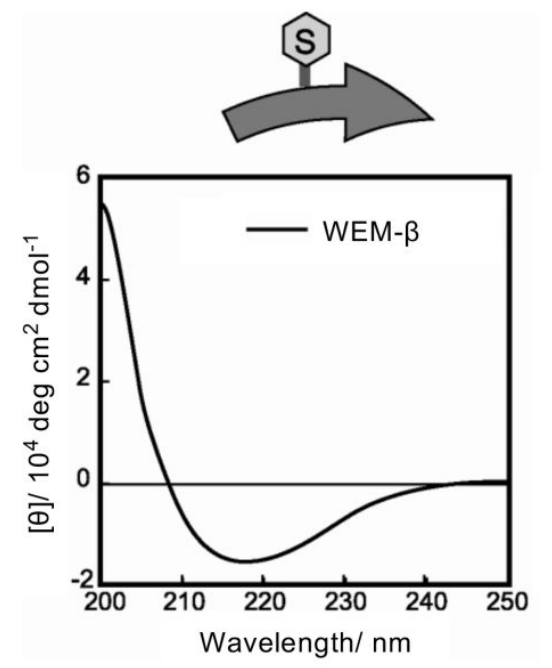

Figure S1 Circular dichroism spectra of designed monosaccharide-modified peptides. [Peptide] $=20 \mu \mathrm{M}$ in $10 \mathrm{mM}$ HEPES (pH 7.4) buffer containing $150 \mathrm{mM} \mathrm{NaCl}, 1 \mathrm{mM} \mathrm{CaCl}$, and $1 \mathrm{mM} \mathrm{MnCl}_{2}$.
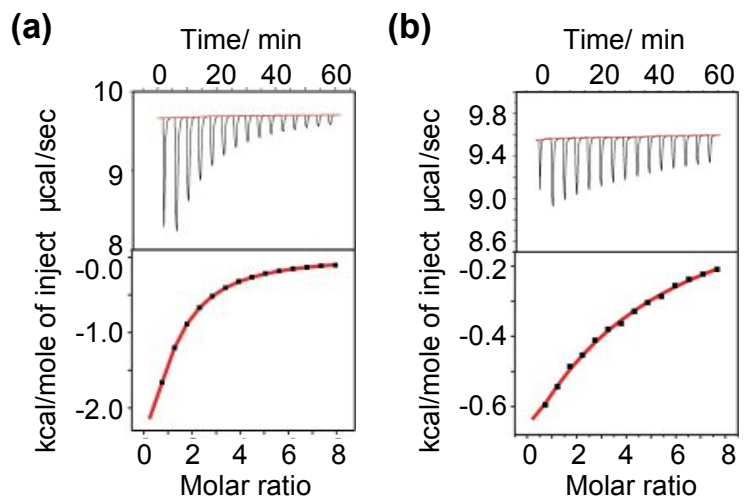

Figure S2 Calorimetric titration profiles of the control saccharides with (a) Me- $\alpha$-Man for Con A and (b) Lac for PNA at $25^{\circ} \mathrm{C}$. 